\title{
UTILIZAÇÃO DO BRINQUEDO TERAPÊUTICO, COMO UM INSTRUMENTO DE INTERVENÇÃO DE ENFERMAGEM, NO PREPARO DE CRIANÇAS SUBMETIDAS A COLETA DE SANGUE*
}

\author{
THE USE OF A THERAPEUTHIC TOY AS AN INSTRUMENT OF NURSING \\ INTERVENTION WHEN PREPARING THE CHILD TO BLOOD COLLECTION
}

\section{UTILIZACIÓN DE UN JUGUETE TERAPEUTICO COMO UN INSTRUMENTO DE INTERVENCIÓN DE ENFERMERÍA, EN EL PREPARO DE NIÑOS SOMETIDOS A LA COLECTA DE SANGRE}

Patricia de Jesus Ribeiro** Ana Llonch Sabatés*** Circéa Amalia Ribeiro****

Ribeiro PJ, Sabatés AL, Ribeiro CA. Utilização do brinquedo terapêutico, como um instrumento de intervenção de enfermagem, no preparo de crianças submetidas à coleta de sangue. Rev Esc Enferm USP 2001; 35(4): 420-8.

\begin{abstract}
RESUMO
O estudo é um quase-experimento, que teve como objetivo verificar o efeito da aplicação do Brinquedo Terapêutico sobre o comportamento de crianças pré-escolares, durante a coleta de sangue para exames laboratoriais. A amostra constituiu-se de 42 crianças divididas nos grupos controle e experimental. Todas as crianças tiveram seu comportamento observado, sendo apenas as do grupo experimental preparadas com o uso do Brinquedo Terapêtico. Os resultados foram analisados comparando-se o comportamento das crianças dos dois grupos e demonstraram que o preparo com o Brinquedo Terapêutico foi eficaz na compreensão do procedimento e no controle de suas reações comportamentais.
\end{abstract}

PALAVRAS-CHAVE: Enfermagem pediátrica. Jogos e brinquedos. Comportamento infantil.

\begin{abstract}
This study is almost an experiment with the objective to verify the effect of the Therapeutic Play on preschool children during blood collect for laboratory tests. The sample consisted of 42 children divided into control and experimental groups. All the children had their behavior observed and only the children of the experimental group were prepared for the Therapeutic Play. The results were analyzed comparing the children's behavior with the groups and showed that arrangement with the Therapeutic Play was effective in the comprehension of the procedure and in the control of their behavioral reactions.
\end{abstract}

KEYWORDS: Pediatric nursing. Play and playthings. Child behavior.

\section{RESUMEN}

Este estudio es un casi-experimento que tuvo como objetivo verificar el efecto de la aplicación del Juguete Terapeutico sobre el comportamiento de niños pre-escolares, durante la colecta de sangre para examines laboratoriales. La muestra se constituyó de 42 niños divididos en dos grupos: de control y experimental. Todos los niños tuvieron un comportamiento observado, siendo solo los del grupo experimental preparados con el uso del Juguete Terapeutico. Los resultados fueron analisados comparándose el comportamiento de los niños de los dos grupos y demonstraron que el preparo con el Juguete Terapeutico fue eficaz en la compreensión y en el control de sus reacciones comportamentales durante el mismo.

PALABRAS-CLAVE: Enfermería pediatrica. Juegos y juguetes. Conducta infantil.

Trabalho apresentado no VIII Congresso de Iniciação Científica da UNIFESP.

Enfermeira. Mestre em Ciências da Saúde. Pós-graduanda da UNIFESP.

*** Enfermeira. Doutora em Enfermagem. Docente da Universidade de Guarulhos.

**** Enfermeira. Doutora em Enfermagem. Docente da UNIFESP 


\section{INTRODUÇÃO}

A doença cujo tratamento determina procedimentos que envolvem a utilização de agulhas constitui uma situação de tensão à criança, especialmente na idade pré-escolar, porque em razão da inabilidade ou falta de oportunidade para verbalizar seus sentimentos e pensamentos, ela pode desenvolver medos e muita ansiedade diante deles.

A criança pré-escolar apresenta limitações em sua capacidade de compreensão dos fatos e situações vivenciadas por causa do seu pensamento fantasioso e egocêntrico (1). Quando hospitalizada, ela sente dificuldade para compreender o que está se passando com ela, tanto no que se refere à doença em si como no que diz respeito aos procedimentos diagnósticos e terapêuticos, aos quais é submetida; por isso, ela apresenta uma grande dificuldade em interagir com seu corpo doente(2).

Uma das formas capazes de ajudar a criança a perceber o que está acontecendo com ela, é o brinquedo terapêutico, que funciona como liberador de seus temores e ansiedades e permite à ela revelar o que ela sente e pensa. O brinquedo terapêutico tem seu uso amplamente preconizado na assistência de enfermagem à criança.

Brinquedo Terapêutico constitui-se num brinquedo estruturado para a criança aliviar a ansiedade causada por experiências atípicas para a idade, que costumam ser ameaçadoras e requerem mais do que recreação para resolver a ansiedade associada, devendo ser utilizado sempre que ela tiver dificuldade em compreender ou lidar com uma experiência dificil ou necessitar ser preparada para procedimentos(3). Deve ser usado pela enfermeira que assiste a criança com o objetivo de dar à ela uma melhor compreensão das suas necessidades (4). Tem também a função de auxiliar no preparo da criança para procedimentos, a fim de descarregar sua tensão após os mesmos, dramatizando as situações vividas e manuseando os instrumentos utilizados ou objetos de brinquedo que os representa (5-6) $\mathrm{O}$ brinquedo normal torna-se terapêutico quando promove o bem-estar psicofisiológico da criança (7)

Distinguem-se três tipos de brinquedo terapêutico: o que permite descarga emocional, também conhecido como brinquedo dramático; o brinquedo instrucional e o brinquedo capacitador de funções fisiológicas ${ }^{(8)}$.

O uso do brinquedo terapêutico na assistência de enfermagem à criança é importante, pois pode facilitar uma resposta positiva da criança durante um procedimento doloroso, após demonstração de comportamentos ou respostas, na brincadeira (9).

Hoje, o brinquedo é amplamente reconhecido como uma forma de comunicação universal das crianças. Nesse sentido, o Brinquedo Terapêutico
Ajuda na comunicação enfermeira- criança durante o preparo para um procedimento doloroso.

Bonecos, agulhas e seringas são objetos úteis para ajudar a criança a compreender uma experiência de punção venosa, bem como obter algum controle sobre suas emoções. As enfermeiras podem usar bonecos e material hospitalar para detectar conceitos equivocados a respeito dos procedimentos e obter informações acerca de seus medos irreais e fantasias ${ }^{(10)}$,

No que se refere à criança doente, o brinquedo apresenta quatro funções: a primeira é permitir liberar a raiva por meio da expressão; a segunda é a repetição de experiências dolorosas a fim de compreendê-las; a terceira é o estabelecimento de um elo entre o lar e o hospital e a quarta função é retrair-se para readquirir controle. Essas quatro funções permitem à criança manipular o seu mundo, bem como obter o controle da situação(11) $^{(11)}$

A relevância dos efeitos do brinquedo terapêutico no preparo de crianças para experiências dolorosas motivou a elaboração deste estudo, que teve como objetivo verificar o efeito da aplicação do Brinquedo Terapêutico sobre o comportamento de crianças, de três a seis anos, durante a coleta de sangue para exames laboratoriais.

\section{CASUÍSTICA E MÉTODO}

Trata-se de uma pesquisa experimental, caracterizando-se com um quase-experimento. Os quase-experimentos carecem de distribuição aleatória ou grupo controle que caracteriza os experimentos verdadeiros (12). Neste estudo, foi predeterminado que as 21 primeiras crianças selecionadas integrariam o grupo experimental e as 21 seguintes o grupo controle.

A pesquisa foi realizada no Laboratório Central de um hospital geral, localizado no Município de São Paulo, campo de ensino teórico-prático para estudantes dos cursos de Enfermagem, Medicina e Fonoaudiologia de uma Universidade Pública, após ter sido aprovado pela Comissão de Ética em Pesquisa da referida instituição.

Nesse local a coleta é realizada por um técnico de laboratório, podendo os pais permanecerem junto à criança durante esse procedimento.

\section{AMOSTRA E VARIÁVEIS SELECIONADAS}

A amostra foi constituída de 42 crianças que compareceram ao Laboratório Central para serem submetidas à coleta de sangue, tendo sido distribuídas em dois grupos iguais, um controle e outro 
experimental e que atendiam aos seguintes critérios de elegibilidade: idade de três a seis anos e estar em condições de brincar, ou seja, não apresentar estado geral grave e estar consciente e contatuando com o meio ambiente.

A fim de se estabelecer a equivalência dos grupos, controle e experimental, decidiu-se conhecer as características dos mesmos relativas à: idade (em anos); sexo e experiências anteriores em coleta de sangue (em número de experiências).

As variáveis estudadas foram: a variável experimental, representada pela introdução do brinquedo terapêutico no preparo de crianças para a coleta de sangue; e a variável dependente, representada pelos comportamentos expressados pelas crianças durante a coleta de sangue, que foram selecionados baseados nas categorizações de comportamentos propostas por outros autores $(1,13)$

\section{Descrição dos comportamentos observados nas crianças}

Com o objetivo de facilitar a observação e identificação destes comportamentos, consideramos importante sua descrição, que apresentamos a seguir. A descrição foi elaborada, segundo padrão anteriormente utilizado para narrar categorias de comportamento de crianças (13).

\section{Comportamentos de Agressão}

Bate: refere-se à ação da criança de bater nas mãos do profissional que porta a seringa e a agulha para a coleta de sangue, com o objetivo de tirá-las de sua direção.

Chuta: refere-se a um movimento rápido com o qual a criança, conseguindo "livrar" suas pernas das pernas da mãe, pai ou responsável, que as comprime, chuta o profissional que realiza a coleta de sangue.

Puxa o braço: refere-se à situação em que a criança retrai rapidamente o braço, segundos antes ou após a inserção da agulha em sua veia.

Empurra: ocorre quando a criança afasta bruscamente, com as mãos, o material que o profissional traz próximo a seu braço, durante a coleta de sangue.

Segura o equipamento: ocorre quando a criança, com uma ou as duas mãos prende ou agarra com força a seringa e a agulha que o profissional traz próximo a seu braço.

Esconde-se: ocorre quando a criança se desloca de um local para outro da sala de coleta de sangue com o objetivo de esconder-se do profissional, que realiza a coleta de sangue.

\section{Comportamentos de Expressão Verbal}

Grita: refere-se ao comportamento de gritar, apresentado pela criança durante ou após a inserção da agulha em sua veia.

Ameaça: ocorre quando a criança ameaça fazer alguma coisa, caso o profissional realize a coleta de sangue.

Discute: refere-se à situação na qual a criança questiona a coleta de sangue, fazendo perguntas ao profissional que a realiza, solicitando uma resposta.

Culpa: ocorre quando a criança verbaliza que o motivo da coleta de sangue é conseqüência de algo que ela fez errado ou deixou de fazer.

Exige: ocorre quando a criança exige a presença de seu pai, de sua mãe ou do responsável, durante a coleta do sangue.

Nega: ocorre quando a criança diz, repetidamente, que não quer que lhe façam o procedimento, antes ou durante a realização do mesmo.

\section{Comportamentos de Movimentação do Corpo}

Fica quieta: refere-se à ausência de movimentos que poderiam dificultar a coleta do sangue. Mantida pela criança, durante a realização do procedimento.

Manipula o corpo: ocorre quando a criança move a mão sobre diferentes partes do corpo, realizando movimentos de manusear, alisar, coçar, passar a mão por, esfregar.

Movimenta-se: ocorre quando a criança realiza qualquer movimento que dificulte a coleta, seja ele de agressão (chutar, empurrar) ou não (movimentos rotacionais com o tórax, puxar o braço).

\section{Comportamentos de Expressão de Emoções}

Chora: refere-se à manifestação de choro intensa pela criança, antes ou durante a coleta do sangue, ou mesmo após o término do procedimento.

Chora baixinho: ocorre quando o choro da criança se manifesta de forma fraca e retraída.

Ri: ocorre quando a criança, além de demonstrar o riso por meio da expressão fisionômica, também dá risadas seguidas.

Sorri: refere-se à expressão fisionômica da criança que denotava alegria, manifestando essa emoção pelo sorriso.

\section{Comportamentos de Dependência}

Agarra-se aos pais: ocorre quando a criança segura ou abraça com força o responsável que a acompanha; e também quando, gritando por socorro, pede ajuda à sua mãe.

Deseja colo: refere-se ao comportamento da criança de, estender os braços na sua direção dos pais ou responsável, solicitando que a pegue no colo. 
MATERIAL E TÉCNICA UTILIZADOS NO PREPARO DA CRIANÇA PARA A COLETA DE SANGUE

O material utilizado para a demonstração da coleta de sangue constituiu-se de: um boneco, uma seringa, um tubo de ensaio, algodão e esparadrapo.

O boneco foi preparado para tornar a demonstração mais próxima da realidade. Para adaptação foram utilizados: um escalpe, um frasco de plástico com capacidade para $10 \mathrm{ml}$ e cola. A parte proximal do escalpe, que continha a agulha, foi inserida no frasco de plástico e colocada no interior da coxa do boneco; a partir dessa região, o cateter, representando a veia do boneco, foi conduzido até o antebraço e sua extremidade distal fixada neste local. Dessa forma, tornou-se possivel a entrada e saída de líquido pelo orificio do escalpe exteriorizado no antebraço do boneco. A seguir, foram injetados mais ou menos $9 \mathrm{ml}$ de líquido de cor vermelha pelo orificio, que ficou depositado no frasco (reservatório de líquido do boneco), e mantido em seu interior. Essa adaptação permitiu que o líquido aspirado simbolizasse o sangue, durante o preparo da criança para o procedimento de coleta de sangue (ANEXO 1).

\section{COLETA DE DADOS}

Para a coleta de dados foi elaborado um instrumento denominado "Ficha de registro dos comportamentos" (ANEXO 2), constituído de duas partes: a primeira identificação, em que foram registrados o nome, idade, sexo, escolaridade e o número de experiências anteriores em coleta de sangue;a segunda registro da observação dos comportamentos durante a coleta de sangue, composta de cinco categorias de comportamentos que foram observados na criança, durante o referido procedimento.

A coleta de dados ocorreu no período de abril a julho de 1998 e realizou-se da seguinte forma: após a seleção da criança, conforme os critérios de elegibilidade, era feito o primeiro contato com a mãe, pai ou responsável para obter seu consentimento. Para as crianças do grupo experimental, era realizado o preparo individual para a coleta de sangue com o uso do brinquedo, acompanhado de uma conversa com a criança (ANEXO 3). Essa demonstração era realizada no boneco e ao término da sessão a criança podia manusear o material.

Para as crianças do grupo controle, que não receberam o preparo com o brinquedo, foram apenas observados e registrados os comportamentos durante a coleta de sangue.

\section{APRESENTAÇÃO E DISCUSSÃO DOS RESULTADOS}

\section{Resultados relativos à equivalência dos dois grupos}

Estes resultados referem-se às variáveis idade, sexo e número de experiências anteriores em coleta de sangue, das crianças de ambos os grupos, os quais serão apresentados em gráficos, seguidos da respectiva discussão. A apresentação dos mesmos pretende não só caracterizar a população estudada, como também demonstrar a equivalência destas características entre as crianças dos dois grupos de estudo.

Gráfico 1 - Distribuição das crianças dos grupos controle e experimental, segundo a idade. São Paulo, 1998.

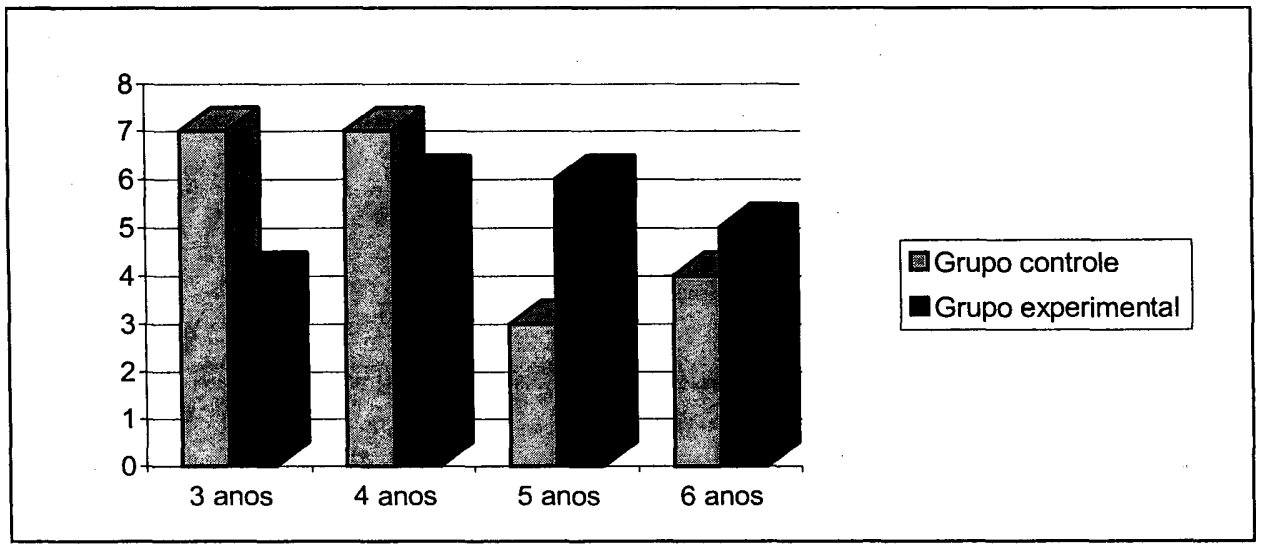

No que se refere à idade, o grupo controle apresentou maior número de crianças na faixa etária de três a quatro anos $(66,66 \%)$ e sua média de idade foi de 4,1 anos; no grupo experimental houve predomínio das idades de quatro e cinco anos $(57,16 \%)$, com uma média de 4,5 anos de idade. 
Gráfico 2 - Distribuição das crianças dos grupos controle e experimental, segundo o sexo. São Paulo, 1998.

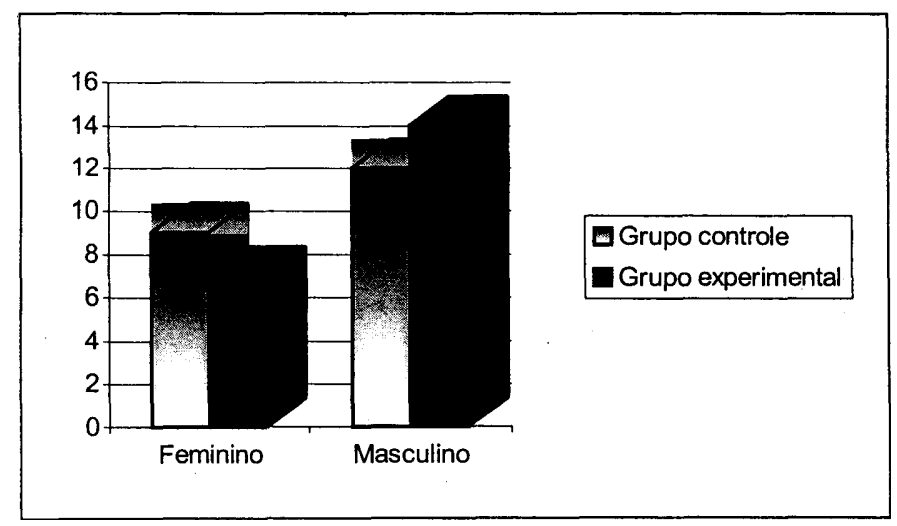

Em relação ao sexo, a maioria das crianças $(57,14 \%)$ do grupo controle e $66,67 \%$ do grupo experimental eram do sexo masculino.

Gráfico 3 - Distribuição das crianças dos grupos controle e experimental, segundo experiências

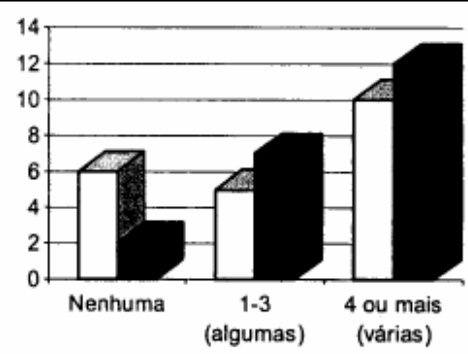

GGrupo controle

Grupo experimental

anteriores em coletas de sangue. São Paulo, 1998.

No que concerne às experiências anteriores em coleta de sangue, a maioria das crianças $(47,62 \%)$ do grupo controle e do grupo experimental $(57,14 \%)$ já haviam tido quatro ou mais experiências anteriores, o que pode estar relacionado à idade das crianças, considerando que aquelas com idade de quatro anos ou mais apresentam maior probabilidade de já terem experienciado situações de exames de sangue.

\section{Resultados relativos aos comportamentos observados}

Esses resultados são apresentados sob a forma de gráficos, de acordo com as categorias de comportamento, e os dados referem-se apenas aos comportamentos manifestados pela criança deste estudo, durante o procedimento de coleta de sangue, motivo pelo qual alguns dos comportamentos descritos (bate e segura o equipamento - categoria agressão; ameaça, discute e culpa-se - categoria expressão verbal; deseja colo categoria dependência) não estão representados nos gráficos
Gráfico 4 - Crianças dos grupos controle e experimental, segundo os comportamentos da categoria agressão. São Paulo, 1998.

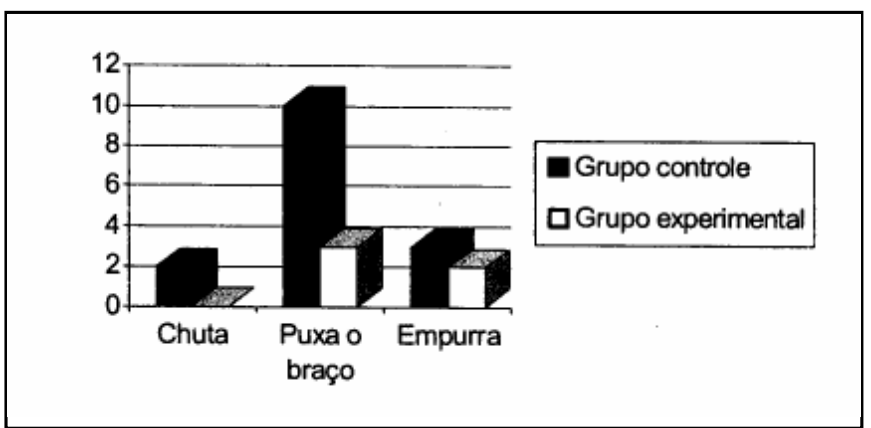

Observa-se, no Gráfico 4, que os três comportamentos de agressão apresentados pelas crianças do estudo manifestaram-se com maior freqüência entre as crianças do grupo controle do que entre as do grupo experimental, destacando-se o comportamento "puxa o braço", presente em 66\% nas do grupo controle. Esses resultados evidenciam que as do grupo experimental colaboraram mais durante a coleta de sangue do que as do grupo controle.

A possibilidade das crianças colaborarem mais durante um procedimento doloroso, pode estar associada à oportunidade que tiveram para dramatizálo antes de vivenciá-lo, e de conhecerem o que lhes irá acontecer, minimizando, assim, a elaboração de fantasias tão comuns nessa idade (14).

Gráfico 5 - Crianças dos grupos controle e experimental, segundo os comportamentos da categoria expressão verbal. São Paulo, 1998.

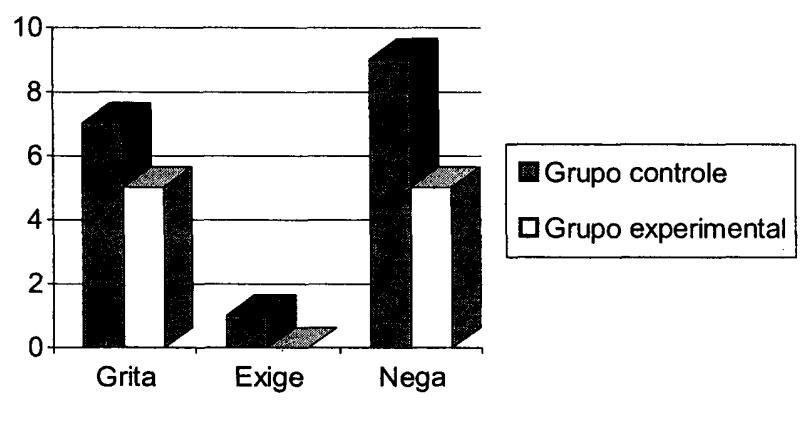

No Gráfico 5, nota-se que o comportamento "nega" foi mais expresso entre as crianças do grupo controle, observando-se menor freqüência dos comportamentos "grita", "exige" e "nega" no grupo experimental do que no grupo controle

Comportamentos como negar, exigir e gritar, são indicativos de que a criança encontra-se em situação de tensão (5). Assim, percebe-se que as crianças do grupo experimental, preparadas com o uso do brinquedo, aparentaram menos tensão que as do grupo controle que não receberam este preparo. 
Gráfico 6 - Crianças dos grupos controle e experimental, segundo os comportamentos da categoria movimentação do corpo. São Paulo, 1998.

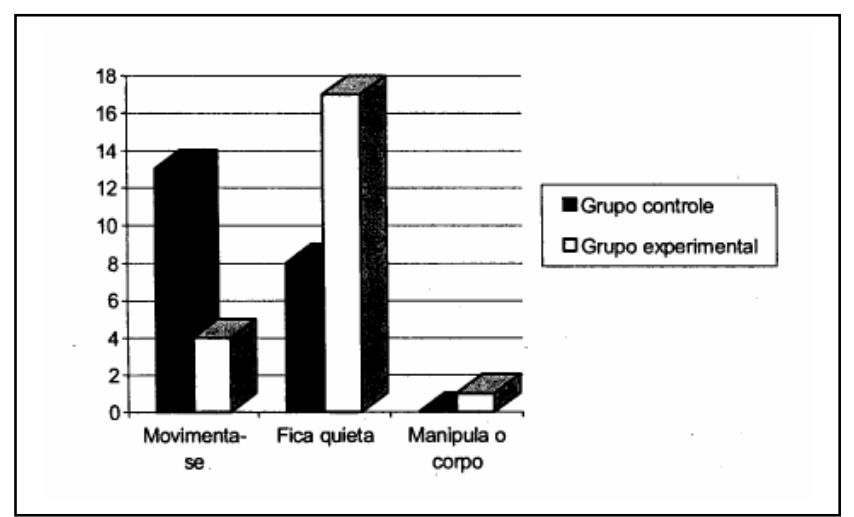

Conforme o Gráfico 6, os comportamentos "movimenta-se", "fica quieta" mostraram diferença importante nas crianças do grupo experimental quando comparadas às do grupo controle. Esses resultados corroboram com os encontrados no Gráfico 4, no sentido de fortalecer a percepção de que as crianças que foram preparadas com o brinquedo terapêutico demonstraram maior capacidade de colaboração, ficando mais quietas, durante o procedimento de coleta de sangue, enquanto as do grupo controle movimentaram-se mais durante o procedimento.

Estudo relativo aos efeitos do brinquedo terapêutico sobre o comportamento de crianças hospitalizadas submetidas à punção venosa, ressalta que essas se tornaram mais cooperativas não necessitando ser restringidas, como ocorrera em punções anteriores, demonstrando uma diminuição do

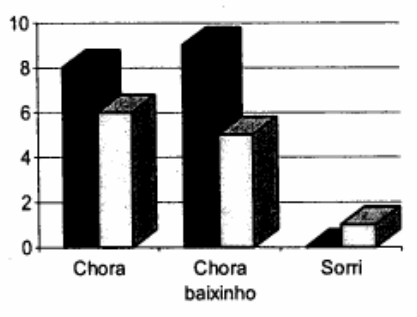

medo relacionado ao procedimento ${ }^{(15)}$.

Gráfico 7 - Crianças dos grupos controle e experimental, segundo comportamentos da categoria expressão de emoção. São Paulo, 1998.

As crianças do grupo experimental, conforme demonstra o Gráfico 7, manifestaram os comportamentos "chora" e "chora baixinho" em menor número do que as do grupo controle e somente entre as daquele grupo observou-se o comportamento "sorri".

Embora o preparo da criança com o brinquedo Rev Esc Enferm USP 2001; 35(4): 420-8. lhe ofereça a oportunidade para expressar suas emoções ela não muda imediatamente de compor-tamento e assim não se deve esperar que não reaja ou não chore durante um procedimento (16). Além disso, é normal crianças expressarem a dor da injeção por meio do choro.

Comparando-se os mesmos comportamentos entre as crianças do mesmo grupo, notou-se que nas do grupo controle "chora baixinho" apresentou-se com maior freqüência que "chora", e nas crianças do grupo experimental ocorreu o inverso. O comportamento de chorar para receber uma injeção é considerado um indicador de progressão positiva do comportamento da criança, se comparado ao choramingar ou chorar baixinho ${ }^{(13)}$

Gráfico 8 Crianças dos grupos controle e experimental, segundo comportamentos da categoria dependência. São Paulo, 1998.

No que se refere à categoria dependência, ilustrada no Gráfico 8, das 42 crianças da amostra apenas uma, do grupo controle, manifestou o

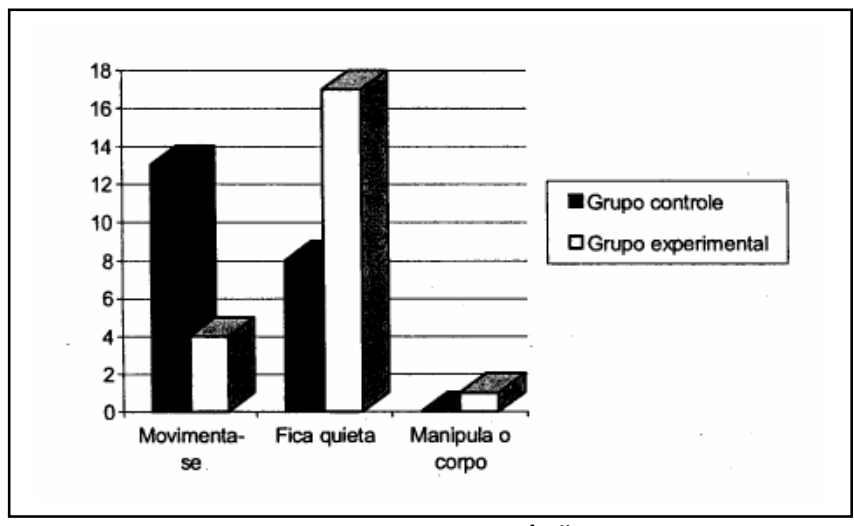

comportamento "agarra-se aos pais". As crianças do grupo experimental não apresentaram comportamentos de dependência.

Embora este resultado possa ser, numericamente, considerado de pouca representa-tividade (5), agarrar-se aos pais é um comportamento da criança que se encontra em estado de tensão.

Analisando os resultados dos comportamentos manifestados pelas crianças de ambos os grupos (controle e experimental), observamos que aquelas preparadas com o uso do brinquedo terapêutico antes do procedimento de coleta de sangue, apresentaram comportamentos de "agressão, expressão verbal, movimentação do corpo, expressão de emoção e dependência" em menor número (grupo experimental) do que as que não foram preparadas (grupo controle). Da mesma forma, houve aumento do comportamento "fica quieta", da categoria movimentação do corpo, também nas crianças do grupo experimental.

Estes achados assemelham-se aos encontrados em vários trabalhos referentes à utilização do brinquedo terapêutico na assistência de enfermagem à criança $(1,6,7,14,15,17-20)$ 
Dessa forma, concluímos que o uso do brinquedo terapêutico, no preparo da criança que necessita ser submetida à coleta de sangue, mostrou-se um instrumento eficaz, que favorece a compreensão e o controle das reações da criança decorrentes dessa situação.

Finalizando consideramos oportuno comentar que embora saibamos da importância da relação entre algumas variáveis relativas às características da amostra e os comportamentos manifestados pelas crianças, não realizamos o estudo de tais correlações em decorrência do tamanho reduzido da amostra. Assim, sugerimos a realização de outros estudos com maior amostragem que possibilitem o estabelecimento de tais relações.

\section{REFERÊNCIAS BIBLIOGRÁFICAS}

(1) Pinheiro MCD, Lopes GT. A influência do brinquedo na humanização da assistência de enfermagem à criança hospitalizada. Rev Bras Enferm 1993; 46(2): 117-31.

(2) Ribeiro CA. Crescendo com a presença protetora da mãe: a criança enfrentando o mistério e o terror da hospitalização. [tese] São Paulo (SP): Escola de Enfermagem da USP; 1999.

(3) Steele S. Child health and the family. New York: Masson; 1981. Concepts of communication; p.710-38.

(4) Green CS. Understanding children's needs through therapeutic play. Nurs 1974; 4(10): 31-2.

(5) Barton PH. Nursing assesment and intervention through play. In: Bergerson BS, Anderson EH, Duffey M, Lohr M, Rose MH. Current concepts in clinical nursing. Saint Louis: Mosby, 1969. p. 203-17.

(6) Clatworth SM. The effect of therapeutic play on the anxiety behaviors of hospitalized children. [Tese] Boston: University School of Education; 1978

(7) Anglin LLV, Sawyer EH. Incorporating play interventions into nursing care. Ped Nurs 1993; 19(5):459-62.

(8) Vessey JÁ, Mahon MM. Therapeutic play and the hospitalized children. J Pediat Nurs 1990; 5(5):1563-68.

(9) Gohsman B, Yunk M. Dealing with the threats of hospitalization. Ped Nurs 1979; 4(5): 32-5.

(10) Jesse PO. Nurses, children and play. Issues Comp Ped Nurs 15(4): 261-69.

(11) Walker C. Use of art and play therapy in pediatric oncology. $J$ Pediatr Oncol Nurs 1989; 6(4): 121-6.

(12) Polit DF, Hungler BF. Fundamentos de pesquisa em enfermagem. $3^{a}$ ed. Porto Alegre: Artes Médicas; 1995.
(13) Ribeiro CA. Comportamento da criança

(14) hospitalizada: proposta de uma categorização. Acta Paul Enferm 1997; 10(1):62-72.

(15) Horta ALM. Influência do tipo de abordagem para injeção intramuscular, nas reações de préescolares. Rev Esc Enferm USP 1989; 23(2): 14963.

(16) Martins MR, Ribeiro CA, Borba RIH, Silva CV Protocolo de preparo da criança pré-escolar para punção venosa, com utilização do brinquedo terapêutico. Rev Latino Am Enferm 2001; 9(2): 7685.

(17) Huerta EDPN. Aprendendo a preparar a criança para enfrentar situações dificeis e/ou desconhecidas. Rev Esc EnfermUSP 1993; 17(1):2732.

(18) Green CS. Larry though puppet play "childish" but it helped him face fears. Nurs $1975 ; .5(3): 30-5$.

(19) Ribeiro CA. O efeito da utilização do brinquedo terapêutico, pela enfermeira pediatra, sobre o comportamento de crianças recémhospitalizadas. Rev Esc Enferm USP 1991; 25(1):4160.

(20) Ribeiro CA. O brinquedo terapêutico na assistência à criança hospitalizada: significado da experiência para o aluno de graduação em enfermagem. Rev Esc Enferm USP 1998; 32(1):73-9.

(21) Santos LMCN, Borba RIH, Sabatés AL. A importância do preparo da criança pré-escolar para injeção intramuscular com o uso do brinquedo. Acta Paul Enferm 2000; 13(2): 52-8. 


\section{ANEXO 1}

PREPARO DA CRIANÇA COM O BRINQUEDO TERAPÊUTICO PARA O PROCEDIMENTO DE COLETA DE SANGUE
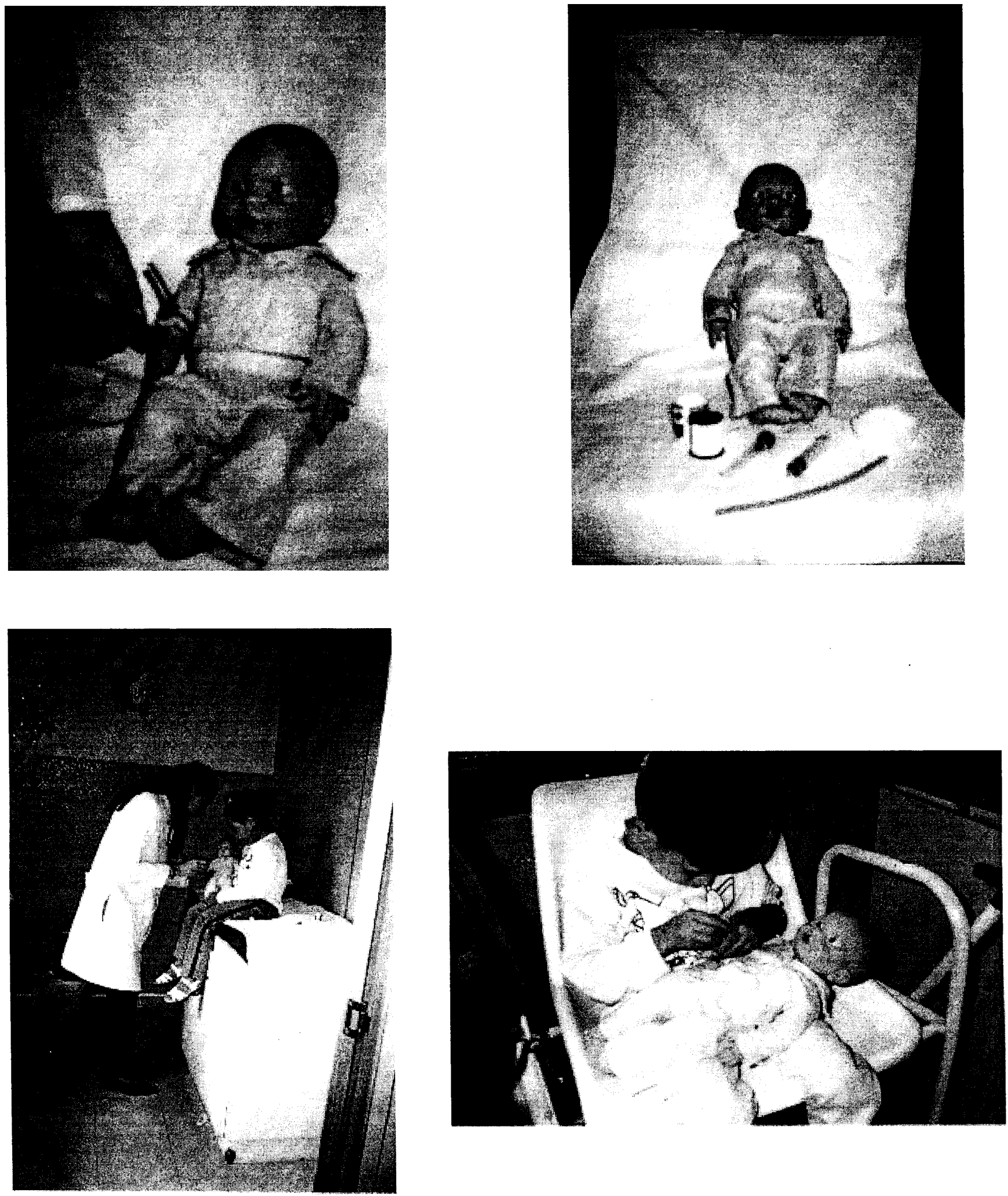


\section{ANEXO 2 \\ FICHA DE REGISTRO DOS COMPORTAMENTOS}

\section{1 - Identificação:}

Nome:

Escolaridade:

Idade:

Sexo:.

Experiências anteriores de coleta de sangue: $>$ nenhuma $>1-3$ (algumas) $>4$ ou mais (várias)

2 - Registro da observação dos comportamentos durante a coleta de sangue:

\begin{tabular}{|l|l|l|l|}
\hline 1- Agressão & 3-Movimentação do corpo & \\
\hline Bate & Manipula o corpo & \\
\hline Chuta & Fica quieta & \\
\hline Puxa o braço & & Movimenta-se & \\
\hline Empurra & & & \\
\hline Segura o equipamento & & 4- Expressão de emoção & \\
\hline & & Chora & \\
\hline 2- Expressão verbal & & Chora baixinho & \\
\hline Grita & & Ri & \\
\hline Ameaça & & Sorri & \\
\hline Discute & & & \\
\hline Culpa & & 5- Dependência & \\
\hline Exige & & Agarra-se aos pais & \\
\hline Nega & & Deseja colo & \\
\hline
\end{tabular}

\section{ANEXO 3}

\section{CONVERSA DE PREPARAÇÃO DA CRIANÇA PARA A COLETA DE SANGUE}

Oi, meu nome é Patrícia!

Daqui a pouco, vão colher um pouquinho do seu sangue para mandar examinar e ver se está tudo bem com você. Você sabe o que é colher sangue?

Para resposta afirmativa:

Então, você quer fazer na boneca o que você acha que vão fazer em você para poder tirar um pouquinho do seu sangue?

Para resposta negativa:

Então, eu vou mostrar para você como vai ser feito na hora de colher um pouquinho do seu sangue:

Primeiro vão examinar seu bracinho e escolher uma veia. Você sabe o que é veia?

Para resposta afirmativa:

Peço para a criança mostrar-me uma das veias de seu braço.

Para resposta negativa:

Mostro, para a criança, uma das veias de seu braço.

Depois vão amarrar essa borrachinha (garrote), no seu bracinho e passar algodão com álcool no local onde vão tirar um pouquinho do seu sangue.

Em seguida, com uma seringa e agulha vão tirar um pouquinho do seu sangue.

Quando terminarem vão colocar um pouquinho de algodão com esparadrapo no local onde tiraram um pouquinho do seu sangue. E o seu sangue será colocado num tubinho (tubo de ensaio), como este, para mandar examiná-lo. 